\title{
Intervention Research on Situational Emotion in Autism
}

\author{
Ting Wang ${ }^{1}$, Yirong $\mathrm{Li}^{1}$, and Jinwen Wang ${ }^{2, *}$ \\ ${ }^{1}$ School of Humanities, Jiangxi University of Traditional Chinese Medicine, Nanchang, China \\ ${ }^{2}$ School of Public Administration, Nanchang University, Nanchang, China
}

\begin{abstract}
Situation emotion understanding is necessary for interpersonal communication and social interaction. Based on the situation of emotion understanding about autistic children literature at home and abroad, this article analyzed the characteristics of autism situational emotion intervention research, including the research object, research purpose, experimental design, data collection method, intervention method, intervention effect and so on. On this basis, some reflections and suggestions are put forward for the followup intervention.
\end{abstract}

\section{Introduction}

Emotion is an essential part of life, which cannot exist without context, so the learning of emotion understanding must understand the elements related to the situation. Situational emotion understanding means that in a specific situation, the individual uses the situation and expression cues to identify the emotions of others and express their own emotions. As an important part of social communication and interaction, situational emotions are not only the basis of individual development and adaptation to society, but also a prerequisite for emotional communication and the establishment of social relationships [1].

Autism is a spectrum disorder that occurs in early childhood and involves varying degrees of combined symptoms. The typical symptoms are the existence of social interaction and communication barriers, and repetitive activities and actions [2]. Dina Tell believes that autistic people are more likely to ignore contextual cues. For example, autistic people will pay attention to the mouth first, while ordinary people rely more on contextual cues [3]. (Table1)

At home and abroad, the situational emotion intervention research of autistic people has achieved certain results, and most of them have achieved ideal intervention effects. Through combing the relevant literature, this paper systematically introduces the characteristics, intervention methods and effects of situational emotional intervention in autistic people, and provides theoretical basis and practical suggestions for the intervention of emotional understanding in future autistic people.

\begin{tabular}{|c|c|c|}
\hline & $\begin{array}{l}\text { Emotion context task } \\
(\max =45)\end{array}$ & 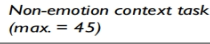 \\
\hline $\begin{array}{l}\text { Controls }(n \\
\text { Mean } \\
\text { SD }\end{array}$ & $\begin{array}{c}39.9 \\
5.09\end{array}$ & $\begin{array}{c}40.2 \\
6.44\end{array}$ \\
\hline $\begin{array}{l}\text { ASD }(n=3 . \\
\text { Mean } \\
\text { SD }\end{array}$ & $\begin{array}{l}39.8 \\
5.53\end{array}$ & $\begin{array}{c}40.9 \\
3.98\end{array}$ \\
\hline $\begin{array}{l}\text { Group comp } \\
\text { Difference } \\
95 \% \mathrm{Cls} \\
P\end{array}$ & $\begin{array}{l}0.10 \\
-2.5,2.7 \\
0.945\end{array}$ & $\begin{array}{c}-0.70 \\
-3.32,1.93 \\
0.599\end{array}$ \\
\hline $\begin{array}{l}\text { Group differ } \\
\text { age, sex, IQ }\end{array}$ & & \\
\hline $\begin{array}{l}\text { Difference } \\
95 \% \mathrm{Cls} \\
P\end{array}$ & $\begin{array}{l}-0.10 \\
-2.29,2.10 \\
0.928\end{array}$ & $\begin{array}{l}-0.88 \\
-3.04,1.28 \\
0.419\end{array}$ \\
\hline
\end{tabular}

\section{The characteristics of the research on situational emotion intervention for autistic patients at home and abroad}

\subsection{Research objects}

Domestic and foreign researchers choose the research objects based on the following points: (1) From the perspective of age, which is concentrated in 4-16 years old. For example: Koning et al. used cognitive behavioral therapy to intervene in social skills for autism in the age range of 10-12 years old [4]. In the study of music intervention for autistic people, the age of the subjects was mainly 3-11 years old [5]. (2)From the perspective of typical symptoms, the subjects must be diagnosed with autistic by a professional institution using a standard scale, and be free from epilepsy, cerebral palsy and other diseases[6-8]. After reviewing the literature, it is found that the scales commonly used to diagnose autism patients at home and abroad include DSM-IV/V , autism diagnosis and observation schedule ADOS-G, and autism diagnosis interview revised version ADI-R. Typicality ensures the consistency of the test group, strengthens the pertinence of the research results, and facilitates the discussion and analysis of the research results. (3)From 
the perspective of participation ability, people with autism who have certain ability to participate are generally selected, and their IQ T score is greater than 70[9-11]. This is to ensure that subjects can cooperate and complete the intervention study, and avoid too many invalid subjects, which will affect the reliability and validity of the intervention results. Therefore, the researcher has certain ability requirements for the autistic subject group.

\subsection{Research purpose: focus on the investigation of the situational emotion itself}

Through the analysis of the literature, it is found that the relevant research purposes are mainly focused on the investigation of the situational emotion understanding itself. By presenting different types of situations, patients are required to identify different situations and make corresponding responses. Response to judge the patient's emotional understanding of the situation. Through literature review, this article finds that the comparative research is mainly from the following five aspects. Firstly, the difference between autistic children and normal children's situational emotional understanding. When most studies explore children's situational emotional understanding, they will compare the understanding of different situations between autistic people and ordinary children. The results show that compared with normal children, children with autism have certain difficulties in understanding situational emotions[12]. Secondly, the basic situational emotions and complex situational emotions. Studies have shown that both autistic and normal children have cognitive deficits in both types of situational emotions, but it is more difficult for autistic children to understand complex situational emotions than basic situational emotions [13]. (Table2)

\begin{tabular}{|c|c|c|c|c|c|c|c|c|c|c|c|c|}
\hline & \multicolumn{4}{|l|}{ Isaal } & \multicolumn{4}{|l|}{ Bititain } & \multicolumn{4}{|l|}{ Sweden } \\
\hline & \multicolumn{2}{|l|}{ Basic } & \multicolumn{2}{|l|}{ Complex } & \multicolumn{2}{|l|}{ Basic } & \multicolumn{2}{|l|}{ Complex } & \multicolumn{2}{|l|}{ Basic } & \multicolumn{2}{|l|}{ Complex } \\
\hline & $\begin{array}{l}\text { ASC } \\
(n=20)\end{array}$ & $\begin{array}{l}\begin{array}{l}\text { TD } \\
(n=22)\end{array} \\
\end{array}$ & $\begin{array}{l}\text { ASC } \\
(n=20)\end{array}$ & $\begin{array}{l}\mathrm{TD} \\
(n=22)\end{array}$ & $\begin{array}{l}\text { ASC } \\
(n=16)\end{array}$ & $\begin{array}{l}\text { TD } \\
(n=18)\end{array}$ & $\begin{array}{l}\text { ASC } \\
(n=16)\end{array}$ & $\begin{array}{l}\begin{array}{l}\text { TD } \\
(n=18)\end{array} \\
\text { (n) }\end{array}$ & $\begin{array}{l}\text { ASC } \\
(n=19)\end{array}$ & $\begin{array}{l}\mathrm{TD}_{(n=18)} \\
\end{array}$ & $\begin{array}{l}\text { ASC } \\
(n=19)\end{array}$ & $\begin{array}{l}\text { TD } \\
(n=18)\end{array}$ \\
\hline Face task & $\begin{array}{l}70 \\
(.18)\end{array}$ & $\begin{array}{l}.86 \\
(.12)\end{array}$ & $\begin{array}{l}.56 \\
(17)\end{array}$ & $\begin{array}{l}.67 \\
(.111)\end{array}$ & $\begin{array}{l}.69 \\
(.14)\end{array}$ & $\begin{array}{l}84 \\
\text { (.13) }\end{array}$ & $\begin{array}{l}59 \\
\text { (12) }\end{array}$ & $\begin{array}{l}.69 \\
(.13)\end{array}$ & $\begin{array}{l}.74 \\
(1.13)\end{array}$ & $\begin{array}{l}.74 \\
(.12)\end{array}$ & $\begin{array}{l}50 \\
(1.5)\end{array}$ & $\begin{array}{l}.65 \\
.(13)\end{array}$ \\
\hline Voice task & $\begin{array}{l}.68 \\
(22)\end{array}$ & $\begin{array}{l}.73 \\
\text { (.13) }\end{array}$ & $\begin{array}{l}57 \\
\text { (24) }\end{array}$ & $\begin{array}{l}72 \\
(.15)\end{array}$ & $\begin{array}{l}.64 \\
\text { (14) }\end{array}$ & $\begin{array}{l}.74 \\
\text { (.16) }\end{array}$ & $\begin{array}{l}68 \\
(17)\end{array}$ & $\begin{array}{l}.71 \\
(.15)\end{array}$ & $\begin{array}{l}.69 \\
(.13)\end{array}$ & $\begin{array}{l}.69 \\
(.13)\end{array}$ & $\begin{array}{l}.59 \\
(23)\end{array}$ & $\begin{array}{l}.73 \\
(.14)\end{array}$ \\
\hline Body task & $\begin{array}{l}.65 \\
(.17)\end{array}$ & $\begin{array}{l}.82 \\
\text { (.11) }\end{array}$ & $\begin{array}{l}.62 \\
(19)\end{array}$ & $\begin{array}{l}76 \\
(.17)\end{array}$ & $\begin{array}{l}.61 \\
\text { (19) }\end{array}$ & $\begin{array}{l}81 \\
(.15)\end{array}$ & $\begin{array}{l}.74 \\
(20)\end{array}$ & $\begin{array}{l}.80 \\
(.18)\end{array}$ & $\begin{array}{l}.69 \\
(17)\end{array}$ & $\begin{array}{l}.76 \\
(.16)\end{array}$ & $\begin{array}{l}57 \\
\text { (23) }\end{array}$ & $\begin{array}{l}.67 \\
\text { (.19) }\end{array}$ \\
\hline Integrative task & $\begin{array}{l}.72 \\
(20)\end{array}$ & $\begin{array}{l}.85 \\
(.14)\end{array}$ & $\begin{array}{l}59 \\
(20)\end{array}$ & $\begin{array}{l}77 \\
\text { (111) }\end{array}$ & $\begin{array}{l}71 \\
(20)\end{array}$ & $\begin{array}{l}84 \\
\text { (.11) }\end{array}$ & $\begin{array}{l}61 \\
(18)\end{array}$ & $\begin{array}{l}.75 \\
(15)\end{array}$ & $\begin{array}{l}.72 \\
(.17)\end{array}$ & $\begin{array}{l}.89 \\
(.12)\end{array}$ & $\begin{array}{l}.49 \\
(.18)\end{array}$ & $\begin{array}{l}.72 \\
(.15)\end{array}$ \\
\hline
\end{tabular}

Thirdly, the positive and negative situational emotions. Most research results show that different situations have different effects on children's emotional understanding, and children's understanding of negative situational emotions is worse than that of positive situational emotions [14]. For autistic children, the result is the same[15]. (Table3)

Table 3 Mean number and SD for the different content statements in the ASD and TD groups

\begin{tabular}{|c|c|c|c|c|c|}
\hline \multirow[t]{2}{*}{ Type of response } & \multicolumn{2}{|c|}{ ASD } & \multicolumn{2}{|l|}{ TD } & \multirow[t]{2}{*}{$\mathbf{U}$} \\
\hline & M & SD & M & SD & \\
\hline Interpersonal & 1.9 & 1.7 & 4.1 & 3.9 & 180.00 \\
\hline Non-social situations & 1.4 & 1.0 & 1.2 & 1.7 & 150.00 \\
\hline Objects & 1.3 & 1.0 & 1.0 & 1.3 & 170.00 \\
\hline Self-awareness & .3 & .7 & .9 & 1.1 & $120.00 *$ \\
\hline Social situations & .2 & .5 & 1.3 & 1.2 & $70.00 * * *$ \\
\hline
\end{tabular}

Fourthly, the emotional aspects of social situations and non-social situations. The current research on the situational emotion of autism is generally aimed at the information processing of a certain situation, and seldom pays attention to the social situation. But there are still some studies that have achieved results. Most studies believe that children with autism are better than social in understanding non-social situations Situational emotions[16-17]. (Table4)

\begin{tabular}{|c|c|c|c|c|}
\hline & ID & ASD & $t$ & Significanee \\
\hline$N$ & 20 & 34 & & \\
\hline Age (years) Mean (SD) [Range] & $15.4(5.8)[8-24]$ & $130(5.4)[8-35]$ & $T_{\mathrm{s},}=1.60$ & $\mathrm{NS}^{\mathrm{e}}$ \\
\hline Full Sall Iot R R & $1096(182)[88-124]$ & $1045(160) 178-1411$ & $t_{10}=133$ & $\mathrm{NS}^{e^{6}}$ \\
\hline Verbal lQ' [Range] & $109.1(9.8)[92-127]$ & $108.7(16.2)[80-140]$ & $t_{21}=0.10$ & $\mathrm{Ns}^{\mathrm{e}}$ \\
\hline Peffomance IQ' [Range] & $1069(8.7)[85-120]$ & $100.1(16.7)(72-139)$ & 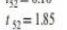 & $\mathrm{NS}^{\mathrm{e}}$ \\
\hline Vineland Socialization Standard Scores R Ranege $^{-}$ & - & $53.4(11.9)[32-75]$ & & \\
\hline ADOs' Communication Algorithm Total [Rangel & - & $4.1(1.2)[2-7]$ & & \\
\hline ADOS Social Algorithm Total [Range] & - & $9.0(24)[5-14]$ & & \\
\hline $\begin{array}{l}\text { ADOS" Both Algorithm Total Rang] } \\
\text { Res }\end{array}$ & - & $131(3.4)[7-21]$ & & \\
\hline ADOS Met criteria for autism (\% of ASD sample) & - & $88 \%$ & & \\
\hline ADOS" Meet criteria for ASD \% o o ASD samplec & - & $100 \%$ & & \\
\hline ADl Met criteria for autism (\% o f ASD smple) & _- & $5 \% \%$ & & \\
\hline
\end{tabular}

\subsection{Experimental design: The main experimental design is to clarify the experimental process and to explore the influence of independent variables on dependent variables}

After reviewing the literature, it is found that the related research on the situational emotional intervention of autistic patients at home and abroad has two main experimental designs: random control experimental design and single subject experimental design. A randomized control group experiment divides the participants into an experimental group and a control group. Then independent variable operations performs on the experimental group, while the control group has no operation. A comparative analysis is performed afterwards to determine the influence of the independent variable on the dependent variable. For example, in the research that situational cues can improve the physical and emotional recognition ability of autistic people, a randomized control group experimental design is also used [18]. The randomized control group experimental design with more sample size requirements, can be used to ensure the balance between different populations, which is more conducive to the reliability and validity of the research, and is convenient for promotion and quantification. The single-subject experimental design is a commonly used experimental design in the face of special groups and small sample research. Its types can be divided into withdrawal design, $\mathrm{ABAB}$ design, and multiple baseline design. In the intervention research on the situational emotion of autistic people, often Using multiple baseline experimental design. Ruixin Ma used a single subject experimental design in his experimental and intervention research on the understanding of emotional situations in autism. The single-subject experimental design has high internal validity and high accuracy, which is more targeted to the autistic group[19].

\subsection{Data collection method: mainly experimental method, supplemented by interview questionnaire method}

Through the analysis of literature, it is found that most domestic and foreign researchers use experimental 
method as the main method of data collection, supplemented by questionnaire survey method. Generally speaking, research is based on experimental methods, and the research methods are slightly different according to different research purposes. On the one hand, in order to understand the current situation of the situational emotional ability of children with autism, the researchers directly tested the subjects and recorded their different reactions[20-21]. On the other hand, in order to help children with autism improve their ability to understand situational emotions, the researchers use experimental intervention to teach situational emotions, including using pictures, music, robots and other materials to improve their ability to recognize situational emotions[22-24]. In addition, the researchers used interviews and questionnaires to collect data to supplement, not only through the people around autistic children to learn more about them, but also interviewed children with autism in order to have a more comprehensive understanding of the situational and emotional understanding of children with autism to increase the credibility of research[25-26].

\subsection{Intervention methods: mainly applied behavior analysis, supplemented by exemplary teaching}

Most domestic and foreign researchers use applied behavior analysis methods to intervene in the emotional understanding of children with autism. Applied behavior analysis includes many kinds of intervention methods, among which, turn-based teaching is its core method and it has a very good effect on the intervention of the situational emotional understanding ability of autistic children. The turn-based teaching intervention method is to decompose the goal into multiple easy subtasks. Each subtask consists of several rounds and each round includes stimulusbehavior-result, with clear beginning and end signs. The basic steps include attracting students' attention-issuing instructions-prompting-reaction-strengthening-pause, repeating each round continuously. Turn-based teaching emphasizes the role of reinforcement in the round, and encouragement and reinforcement are given in time after the subjects make the correct response, which will increase the possibility of correct response in similar situations. Researchers usually use pictures or videos to intervene in a combination of round demonstration teaching[27-29]. In addition to using turn-based teaching to intervene in the understanding of situational emotions in children with autism, researchers have also used exemplary teaching methods in recent years. It includes video demonstration teaching and on-site demonstration teaching. The content of intervention mainly includes facial emotion understanding and naming, situational emotion understanding, emotional response, etc. [30]. Exemplary teaching aims at children imitating in real situations and improving their ability to imitate, so that children can also make correct responses in similar situations and improve external validity[31-32].(Figure1)

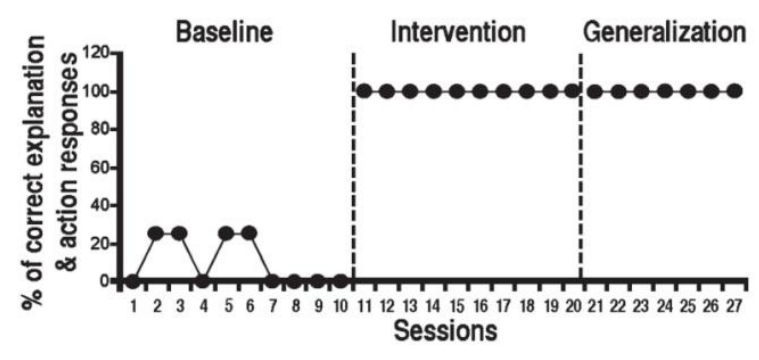

FIGURE 1 Alan's correct explanations and action responses.

\subsection{Intervention effect: Both direct intervention and indirect intervention have better effects}

Intervention research on autism situational emotion can be divided into direct intervention research and indirect intervention research. Direct intervention refers to an intervention method that directly interferes with the situational emotion of autistic people through intervention media such as pictures and videos[33]. Indirect intervention refers to an intervention method that uses music, robots, VR and other intervention media to interfere with the social situation recognition ability of autistic people and then interfere with the situational emotions. Among them, the direct intervention media are mainly pictures and videos. The intervention media of indirect intervention are mainly robots, music and VR technology[34].

\section{Summary and recommendations}

\subsection{Summary}

This article is different from the previous review of autism situational emotions, but focuses on the characteristics of autism situational emotion intervention research, including the research object, research purpose, experimental design, data collection method, intervention method, intervention effect. It has systematically summarized and combed the characteristics of the situational emotion intervention research of autistic people at home and abroad, and improved and enriched the theoretical research on the situational emotion of autistic people from different angles, which is conducive to people's situational emotion of autism. A comprehensive understanding is helpful to the germination and innovation of research on emotional intervention in autism situations.

\subsection{Limitations}

Although many achievements have been made in the current research on the ability of situational emotion understanding in children with autism, there are still some limitations. Firstly, in terms of experimental materials, my country does not have comprehensive and standardized situational emotional intervention materials. Secondly, in terms of research objects, due to the 
particularity of children with autism, there are many difficulties when selecting research objects and testing research objects, such as the small number of research subjects and differences in ability. Finally, in terms of teaching methods, the current intervention research is mainly based on turn-based teaching, supplemented by exemplary teaching, both of which are led by teachers. Students learn under the guidance of teachers, which is not conducive to students' interest and initiative.

\subsection{Suggestions}

Aiming at the current limitations, we put forward some suggestions that are conducive to experimentation and teaching. Firstly, in terms of materials, on the one hand, researchers can produce more standardized video materials. On the other hand, researchers can make full use of VR technology to simulate real situations, link research with the actual lives of children with autism, and improve the ecological validity of the research. Secondly, in terms of research objects, future research needs to select more children with autism for testing to improve the internal and external validity of the experiment. Finally, in terms of teaching methods, in future research, researchers need to comprehensively use various intervention methods and create new intervention methods to stimulate students' interest in learning and improve learning efficiency.

\section{Acknowledgements}

This research was financially supported by Jiangxi Social Science Foundation Project of China(20JY20) and Jiangxi Provincial planning of educational science general project of China (19YB015).

\section{Reference}

1. Fu Xiaolan. Emotional Psychology.Shanghai: East China Normal University Press,2015.184.

2. Speaks A. What is autism. Retrieved on November, 2011, 17: 2011.

3. Tell D. Recognition of emotions from facial expression and situational cues in children with autism. Doctor of Philosophy (PhD). America : Loyola University Chicago, 2009.

4. Koning C , Magill-Evans J , Volden J , et al. Efficacy of cognitive behavior therapy-based social skills intervention for school-aged boys with autism spectrum disorders. Research in Autism Spectrum Disorders, 2013, 7(10):1282-1290.

5. Simpson K, Keen D. Music interventions for children with autism: narrative review of the literature. Journal of autism and developmental disorders, 2011, 41(11): 1507-1514.

6. Hui Li, Weiting Shao, Sheng Xu.A review of research on situational emotional understanding in autistic children. Modern Special Education,2020(02):68-74.

7. Rispoli K M, Malcolm A L, Nathanson E W, et al.
Feasibility of an emotion regulation intervention for young children with autism spectrum disorder: A brief report. Research in Autism Spectrum Disorders, 2019,11(67):101420

8. Huiping Liu, Chuanshi Liu.Intervention study of dynamic picture combined with turn-based instruction on emotion recognition ability of autistic children.Special Education in China,2020(01):45-50.

9. Hemin Li. An experimental and intervention study on situational information processing in children with autism. Master thesis. Shanghai: East China Normal University,2018.

10. Ruixin Ma. An experimental and intervention study on emotional situation understanding in children with autism. Master thesis. Shanghai: East China Normal University,2018.

11. Mackay T, Knott F , Dunlop, Aline - Wendy. Developing social interaction and understanding in individuals with autism spectrum disorder: A groupwork intervention. Journal of Intellectual \& Developmental Disability, 2007, 32(4):279-290.

12. Fei Li,Qin-yu Shen, Yi-lin Tang et al. Emotional understanding of situational events in children with autism: Implicit and explicit measures. Psychological Science,2019,42(5):1267-1273.

13. Fridenson - Hayo S, Berggren S, Lassalle A, et al . Basic and Complex Emotion recognition in Children With Autism: Cross - cultural Findings . Molecular Autism, 2016, 7( 1) : 52.

14. Guoxiong Liu, Fuxi Fang,Jia Zhao. Children's cognition and attribution of emotions in different situations. Acta Psychologica Sinica,2006,38(2) : 216-222.

15. Ben - Itzchak E, Abutbul S, Bela H, et al . Understanding One's Own Emotions in Cognitively - Able Preadolescents With Autism Spectrum Disorder. Journal of Autism and Developmental Disorders,2016,46( 7) : 2363 - 2371.

16. Klin A ,Jones W. Attributing social and physical meaning to ambiguous visual displays in individuals with higher-functioning autism spectrum disorders. Brain and Cognition Volume, 2006,61 (1) : 40-53.

17. Guillon Q, Hadjikhani N. Visual social attention in Autism Spectrum Disorder: insights from eye tracking studies. Neuroscience \& Biobehavioral Reviews,2014,42(5):279-297.

18. Metcalfe D, McKenzie K, McCarty K, et al. Emotion recognition from body movement and gesture in children with Autism Spectrum Disorder is improved by situational cues[J]. Research in Developmental Disabilities, 2019, 86: 1-10.

19. Wang M, Reid D. Using the virtual reality-cognitive rehabilitation approach to improve contextual processing in children with autism. The Scientific World Journal, 2013:716890.

20. Fridenson-Hayo S, Berggren S, Lassalle A, et 
al . Basic and Complex Emotion recognition in Children With Autism: Cross - cultural Findings . Molecular Autism, 2016, 7( 1): 52.

21. Tell D. Recognition of Emotions From Facial Expression and Situational Cues in Children with Autism.America:Loyola University Chicago,2009.

22. Wenyao Huo, Yanhong Liu, Xiaoyi Hu .Intervention study on facial expression recognition in autistic children.Chinese Journal of Special Education,2016,(7) : 52-58.

23. Mchugh L, Bobarnac A, Reed P. Brief Report: Teaching Situation - Based Emotions to Children With Autistic Spectrum Disorder. Journal of Autism Developmental Disorders, 2011,41( 10) : 1423 - 1428.

24. Adams A,Robinson P. An Android Head for Social Emotional Intervention for Children With Autism Spectrum Conditions. Mello S D. Affective Computing and Intelligent Interaction: Forth International Conference. Memphis: Springer Berlin Heidelberg, 2011: 183-190.

25. Ruixin Ma. An experimental and intervention study on emotional situation understanding in children with autism. Master thesis. Shanghai: East China Normal University,2018.

26. Ben-Itzchak E, Abutbul S, Bela $\mathrm{H}$, et al. Understanding One's Own Emotions in Cognitively - Able Preadolescents With Autism Spectrum Disorder. Journal of Autism and Developmental Disorders, 2016,46( 7) : 2363 - 2371.

27. Wenyao Huo, Yanhong Liu , Xiaoyi Hu .Intervention study on facial expression recognition in autistic children.Chinese Journal of Special Education,2016,(7) : 52-58.

28. Ruixin Ma. An experimental and intervention study on emotional situation understanding in children with autism. Master thesis. Shanghai: East China Normal University,2018.

29. Matsuda S, Yamamoto J . Computer - based Intervention for Inferring Facial Expressions From the Socio - emotional Context in Two Children With Autism Spectrum Disorders . Research in Autism Spectrum Disorders, 2014,8( 8) : 944 - 950.

30. Hui Li, Weiting Shao, Sheng Xu.A review of research on situational emotional understanding in autistic children. Modern Special Education,2020(02):68-74.

31. Gena A, Krantz P J, McClannahan LE, et al .Training and Generalization of Affective Behavior Displayed by Youth With Autism. Journal of Applied Behavior Analysis, 1996,29( 3) : 291-304.

32. Bernad - Ripoll S . Using a Self - as - Model Video Combined With Social Stories TM to Help a Child With Asperger Syndrome Understand Emotions. Focus on Autism and Other Developmental Disabilities,2007,22( 2) : $100-106$.
33. Golan O, Ashwin E, Granader Y, et al. Enhancing emotion recognition in children with autism spectrum conditions: An intervention using animated vehicles with real emotional faces. Journal of autism and developmental disorders, 2010, 40(3): 269-279.

34. Marino F, Chilà $\mathrm{P}$, Sfrazzetto $\mathrm{S} T$, et al. Outcomes of a robot-assisted social-emotional understanding intervention for young children with autism spectrum disorders. Journal of autism and developmental disorders, 2020, 50(6): 1973-1987. 